\title{
A Novel Predictive Model for In-Hospital Mortality Based on a Combination of Multiple Blood Variables in Patients with ST-Segment-Elevation Myocardial Infarction
}

\author{
Yuhei Goriki ${ }^{1,2}$, Atsushi Tanaka ${ }^{2}$ *(D), Kensaku Nishihira ${ }^{1}$, Atsushi Kawaguchi ${ }^{3}$, \\ Masahiro Natsuaki ${ }^{2}$, Nozomi Watanabe ${ }^{1}{ }^{(\mathbb{D}}$, Keiichi Ashikaga ${ }^{1}$, Nehiro Kuriyama ${ }^{1}$, \\ Yoshisato Shibata ${ }^{1}$ and Koichi Node ${ }^{2}$ \\ 1 Miyazaki Medical Association Hospital Cardiovascular Center, Miyazaki 880-0834, Japan; \\ i03.eou2@gmail.com (Y.G.); nishihira@med.miyazaki-u.ac.jp (K.N.); n_watanabe@cure.or.jp (N.W.); \\ ashikaga@cure.or.jp (K.A.); n-kuriyama@cure.or.jp (N.K.); yshibata@cure.or.jp (Y.S.) \\ 2 Department of Cardiovascular Medicine, Saga University, Saga 849-8501, Japan; \\ natsuaki@kuhp.kyoto-u.ac.jp (M.N.); node@cc.saga-u.ac.jp (K.N.) \\ 3 Clinical Research Center, Saga University Hospital, Saga 849-8501, Japan; akawa@cc.saga-u.ac.jp \\ * Correspondence: tanakaa2@cc.saga-u.ac.jp; Tel.: +81-952-34-2364
}

Received: 14 February 2020; Accepted: 17 March 2020; Published: 20 March 2020

\begin{abstract}
In emergency clinical settings, it may be beneficial to use rapidly measured objective variables for the risk assessment for patient outcome. This study sought to develop an easy-to-measure and objective risk-score prediction model for in-hospital mortality in patients with ST-segment elevation myocardial infarction (STEMI). A total of 1027 consecutive STEMI patients were recruited and divided into derivation $(n=669)$ and validation $(n=358)$ cohorts. A risk-score model was created based on the combination of blood test parameters obtained immediately after admission. In the derivation cohort, multivariate analysis showed that the following 5 variables were significantly associated with in-hospital death: estimated glomerular filtration rate $<45 \mathrm{~mL} / \mathrm{min} / 1.73 \mathrm{~m}^{2}$, platelet count $<15 \times 10^{4} / \mu \mathrm{L}$, albumin $\leq 3.5 \mathrm{~g} / \mathrm{dL}$, high-sensitivity troponin I $>1.6 \mathrm{ng} / \mathrm{mL}$, and blood sugar $\geq 200 \mathrm{mg} / \mathrm{dL}$. The risk score was weighted for those variables according to their odds ratios. An incremental change in the scores was significantly associated with elevated in-hospital mortality $(p<0.001)$. Receiver operating characteristic curve analysis showed adequate discrimination between patients with and without in-hospital death (derivation cohort: area under the curve (AUC) 0.853; validation cohort: AUC 0.879), and there was no significant difference in the AUC values between the laboratory-based and Global Registry of Acute Coronary Events (GRACE) score $(p=0.721)$. Thus, our laboratory-based model might be helpful in objectively and accurately predicting in-hospital mortality in STEMI patients.
\end{abstract}

Keywords: ST-segment-elevation myocardial infarction; risk score; in-hospital mortality

\section{Introduction}

Acute myocardial infarction (AMI) remains a worldwide leading cause of high mortality [1]. Over the last 2 decades, advances in the coronary care unit and primary reperfusion therapy have improved the outcome of the chronic phase after an AMI [2]. Although the incidence of in-hospital death in patients with AMI also declined up to the first decade of the twenty-first century [3,4], thereafter improvement in mortality appeared to plateau [5]. Intriguingly, the incidence of in-hospital death in Japan has been significantly higher in patients with ST-segment elevation myocardial infarction (STEMI) than in patients with non-STEMI (7.7\% vs. $5.1 \%)$, despite the recently introduced settings of optimal 
medical therapy and successful reperfusion after primary percutaneous coronary intervention (PCI) [6]. Additionally, the shortening of door-to-balloon times in patients with STEMI was not associated with improved short- and long-term clinical outcomes, which suggests a need for additional strategies $[7,8]$. Thus, the increased accuracy of prompt risk stratification in the emergency department might aid in improving the outcome of patients with AMI during the acute phase, especially in patients with STEMI. Accurate risk stratification should raise an important implication in the management of these patients.

The Thrombolysis in Myocardial Infarction (TIMI) risk score and the Global Registry of Acute Coronary Events (GRACE) risk score have been reported to be useful risk stratification tools for in-hospital mortality in patients with AMI $[9,10]$. Of these risk scores, the GRACE risk score is known to have the highest validity [11,12]. The GRACE risk score requires 8 variables to assess risk of in-hospital mortality, as follows: age, heart rate, systolic blood pressure, Killip classification, cardiac arrest at hospital admission, initial serum creatinine level, elevated levels of cardiac markers, and ST-segment deviation. However, the heart rate and systolic blood pressure sometimes vary widely during the acute phase, and the Killip classification is a subjective evaluation. Therefore, performing an assessment of these variables in the emergency setting sometimes proves difficult. By contrast, blood parameters can be quickly measured and provide objective information, even in the emergency setting. Several biomarkers have been reported to be potential tools for predicting in-hospital mortality in patients with AMI [13-20]. Given that these biomarkers can reflect different aspects of pathophysiological responses that occur during the post-AMI phase, a combination of biomarkers might provide more accurate and useful information for risk stratification than the information provided by any individual biomarker. Therefore, the aim of this study was to develop a novel, easy-to-measure, and objective risk-score prediction model for in-hospital mortality in patients with STEMI that was based on a combination of parameters obtained on routine blood tests, and to compare the predictive utility of the new model with that of the conventional GRACE score.

\section{Methods}

\subsection{Study Design and Population}

This was a single-center, retrospective observational study undertaken in Japan. A total of 1252 consecutive patients who were admitted to Miyazaki Medical Association Hospital for STEMI between April 2012 and May 2019 were enrolled in the study. Exclusion criteria included the following: (1) not receiving primary PCI; (2) onset-to-admission time $>48 \mathrm{~h}$; (3) lack of blood test results. A total of 1027 patients were finally included in the study. Based on the date of hospital admission, they were divided into 2 groups, the derivation and validation sets, which consisted of 669 patients hospitalized from April 2012 to December 2016 and 358 patients hospitalized from January 2017 to May 2019, respectively (Figure 1). The protocol of the study was approved by the Institutional Review Board at Miyazaki Medical Association Hospital (2019-30).

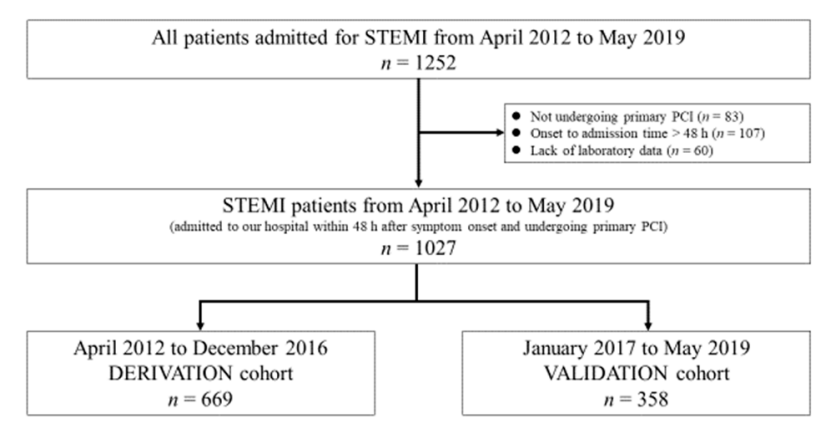

Figure 1. Flow diagram of patient enrollment in the study. PCI, percutaneous coronary intervention; STEMI, ST-segment elevation myocardial infarction. 


\subsection{Diagnosis of STEMI}

STEMI was diagnosed according to the universal definition of MI described by the European Society of Cardiology and the American Heart Association [21]. After urgent admission to our hospital and within $48 \mathrm{~h}$ after onset of symptoms, all the patients who were suspected to have STEMI, according to the clinical manifestations such as changes in the electrocardiogram and elevated cardiac enzymes, received emergency coronary angiography and subsequent coronary revascularization. Reperfusion therapy was performed along with primary PCI according to the relevant guidelines and recommendation [1]. The patients then received optimal medications.

\subsection{Data Collection}

The following types of data were collected: demographic characteristics of study patients, medical history, presenting signs and symptoms, results of blood tests, transthoracic echocardiographic and electrocardiographic findings, cardiac procedures, and in-hospital outcome.

Transthoracic echocardiography was performed for all patients immediately after admission, and left ventricular ejection fraction (LVEF) was estimated by the standard biplane Simpson method. The white blood cell (WBC) count (Sysmex XN-1000 ${ }^{\mathrm{TM}}$ (Sysmex Corporation, Hyogo, Japan)); platelet count (Sysmex XN-1000 ${ }^{\mathrm{TM}}$ (Sysmex Corporation, Hyogo, Japan)); and levels of hemoglobin (Sysmex $\mathrm{XN}-1000^{\mathrm{TM}}$ (Sysmex Corporation, Hyogo, Japan)), C-reactive protein (CRP, BioMajesty ${ }^{\mathrm{TM}}$ Series JCA-BM6010 (JEOL Ltd., Tokyo, Japan)), creatinine (BioMajesty ${ }^{\text {TM }}$ Series JCA-BM6010 (JEOL Ltd., Tokyo, Japan)), creatine kinase (CK, BioMajesty ${ }^{\mathrm{TM}}$ Series JCA-BM6010 (JEOL Ltd., Tokyo, Japan)), blood sugar (BS, BioMajesty ${ }^{\mathrm{TM}}$ Series JCA-BM6010 (JEOL Ltd., Tokyo, Japan)), HbA1c (HLC-723 ${ }^{\circledR}$ G9 analyzer (Tosho Bioscience, Tokyo, Japan), albumin (BioMajesty ${ }^{\mathrm{TM}}$ Series JCA-BM6010 (JEOL Ltd., Tokyo, Japan)), uric acid (BioMajesty ${ }^{\mathrm{TM}}$ Series JCA-BM6010 (JEOL Ltd., Tokyo, Japan)), low-density lipoprotein cholesterol (LDL-CHO, BioMajesty ${ }^{\mathrm{TM}}$ Series JCA-BM6010 (JEOL Ltd., Tokyo, Japan)), high-density lipoprotein cholesterol (HDL-CHO, BioMajesty ${ }^{\mathrm{TM}}$ Series JCA-BM6010 (JEOL Ltd., Tokyo, Japan)), high-sensitivity troponin I (hsTnI, ARCHITECT ${ }^{\circledR}$ high sensitive troponin I (Abbott Japan, Tokyo, Japan) on an ARCHITECT ${ }^{\circledR}$ i1000SR analyzer (Abbott Japan, Tokyo, Japan)), and brain natriuretic peptide (BNP, AIA ${ }^{\circledR}-900$ analyzer (Tosho Bioscience, Tokyo, Japan)) were measured in blood specimens obtained immediately after admission. The estimated glomerular filtration rate (eGFR) was calculated using the revised equation for the Japanese population [22].

\subsection{Statistical Analysis}

Continuous variables are reported as means \pm standard deviation for normally distributed values and as medians (interquartile range) for non-normal values. Categorical variables are expressed as numbers and percentages. Comparisons of continuous variables between groups were performed by the Student t-test or Mann-Whitney U test, as appropriate. Comparisons of categorical variables were assessed by the chi-squared or Fisher exact test, as appropriate. Univariate logistic regression analysis was used to calculate the effects of multiple variables on in-hospital death. Potential risk markers were eliminated by multivariate logistic regression using stepwise factor elimination. An odds ratio (OR) was obtained for each significant variable. Based on the OR obtained by multivariate logistic regression, the risk factors for in-hospital death were assigned weighted integers $(\mathrm{OR}<3$ $=1$ point, $\mathrm{OR} \geq 3=2$ points). The patients were then classified into 3 groups according to the risk score, as follows: low-risk ( 0 to 1 point), moderate-risk ( 2 to 4 points), and high-risk group ( $\geq 5$ points). Receiver operating characteristic curve analysis was used to evaluate the effectiveness of the risk score for predicting in-house mortality, and the area under the curve (AUC) was used to determine the predictability of the risk score. We calculated the AUC of the GRACE score and compared it with that of the risk score. The analyses were performed by the JMP software program, version 14.2.0 (SAS Institute Inc., Cary, NC, USA). $p$-values $<0.05$ were considered statistically significant. 


\section{Results}

\subsection{Patient Characteristics}

A total of 1027 patients (669 in the derivation cohort and 358 in the validation cohort) were enrolled in this analysis. Table 1 shows the patients' admission characteristics as stratified into study cohorts. No significant differences were seen between the derivation and validation cohorts for the clinical parameters, with the exception of smoking history; or for vital signs or laboratory data. No significant differences in the clinical parameters related to the treatments for STEMI were observed between the 2 cohorts. Overall, 57 (5.6\%) in-hospital deaths were observed in the study. There was no significant difference in the onset-to-admission time between in-hospital survival and death groups in the overall cohort (survivor, median $200 \mathrm{~min}$ (interquartile range 115-385) vs. death, $260 \mathrm{~min}$ (145-630), $p=0.062$ ).

Table 1. Baseline characteristics of patients subdivided into derivation and validation cohorts.

\begin{tabular}{|c|c|c|c|}
\hline Variables & $\begin{array}{c}\text { Derivation Cohort } \\
\quad(n=669)\end{array}$ & $\begin{array}{l}\text { Validation Cohort } \\
\quad(n=358)\end{array}$ & $p$-Value \\
\hline Age, yr & $68.5 \pm 12.6$ & $68.9 \pm 13.0$ & 0.738 \\
\hline Male, $n(\%)$ & $493(73.7)$ & $257(71.8)$ & 0.297 \\
\hline Body mass index, $\mathrm{kg} / \mathrm{m}^{2}$ & $23.8 \pm 3.6$ & $24.0 \pm 3.9$ & 0.228 \\
\hline Systolic BP, mm Hg & $138.2 \pm 33.4$ & $134.9 \pm 32.9$ & 0.488 \\
\hline Heart rate, beats/min & $77.0 \pm 21.4$ & $76.7 \pm 21.1$ & 0.583 \\
\hline \multicolumn{4}{|l|}{ Medical history } \\
\hline Hypertension, $n(\%)$ & 459 (68.6) & $232(64.8)$ & 0.161 \\
\hline Dyslipidemia, $n(\%)$ & $352(52.6)$ & $185(51.6)$ & 0.472 \\
\hline Diabetes mellitus, $n(\%)$ & $192(28.7)$ & $114(31.8)$ & 0.121 \\
\hline Smoking, $n(\%)$ & $328(49.0)$ & 198 (55.3) & 0.032 \\
\hline Previous MI, $n(\%)$ & $59(8.8)$ & $28(7.8)$ & 0.297 \\
\hline Previous PCI, $n(\%)$ & $69(10.3)$ & $37(10.3)$ & 0.777 \\
\hline Previous CABG, $n(\%)$ & $7(1.0)$ & $3(0.8)$ & 0.777 \\
\hline \multicolumn{4}{|l|}{ Laboratory data } \\
\hline $\mathrm{WBC}, \times 10^{2} / \mu \mathrm{L}$ & $106.7 \pm 38.0$ & $104.4 \pm 37.3$ & 0.472 \\
\hline Hemoglobin, g/dl & $13.9 \pm 2.2$ & $13.9 \pm 2.1$ & 0.885 \\
\hline Platelet, $\times 10^{4} / \mu \mathrm{L}$ & $21.9 \pm 6.6$ & $22.0 \pm 5.8$ & 0.459 \\
\hline $\mathrm{HbA} 1 \mathrm{c}, \%$ & $5.9(5.6-6.5)$ & $6.0(5.6-6.5)$ & 0.235 \\
\hline $\mathrm{BS}, \mathrm{mg} / \mathrm{dL}$ & $156(130-200)$ & $156(130-200)$ & 0.275 \\
\hline $\mathrm{eGFR}, \mathrm{mL} / \mathrm{min} / 1.73 \mathrm{~m}^{2}$ & $67.4 \pm 24.1$ & $65.2 \pm 21.3$ & 0.334 \\
\hline LDL-CHO, mg/dL & $121.1 \pm 35.7$ & $122.6 \pm 34.8$ & 0.685 \\
\hline $\mathrm{HDL}-\mathrm{CHO}, \mathrm{mg} / \mathrm{dL}$ & $46.1 \pm 11.6$ & $47.4 \pm 12.8$ & 0.577 \\
\hline Albumin, mg/dL & $4.0 \pm 0.5$ & $4.0 \pm 0.5$ & 0.877 \\
\hline Uric acid, mg/dL & $6.0 \pm 1.6$ & $5.8 \pm 1.5$ & 0.236 \\
\hline $\mathrm{CRP}, \mathrm{mg} / \mathrm{dL}$ & $0.13(0.06-0.42)$ & $0.13(0.06-0.39)$ & 0.303 \\
\hline $\mathrm{CK}, \mathrm{U} / \mathrm{L}$ & $154(96-411)$ & $162(97-413)$ & 0.581 \\
\hline $\begin{array}{l}\text { High-sensitivity troponin I, ng/mL } \\
\text { (upper limit of normal: } 0.032 \text { ) }\end{array}$ & $0.27(0.04-2.64)$ & $0.26(0.05-2.58)$ & 0.529 \\
\hline $\begin{array}{c}\text { BNP, pg/mL } \\
\text { (upper limit of normal: 18.4) }\end{array}$ & $47.0(18.2-151.7)$ & $45.1(17.2-152.5)$ & 0.401 \\
\hline \multicolumn{4}{|l|}{ Killip classification } \\
\hline I, II, III, IV, $n$ & $535 / 74 / 25 / 35$ & $292 / 28 / 15 / 22$ & 0.319 \\
\hline Onset-to-admission time, min & $200(110-400)$ & $200(115-392)$ & 0.381 \\
\hline LVEF (on admission), \% & $50.6 \pm 11.5$ & $48.9 \pm 10.0$ & 0.321 \\
\hline \multicolumn{4}{|l|}{ Culprit lesion } \\
\hline LMT, $n(\%)$ & $20(2.9)$ & $5(1.4)$ & 0.084 \\
\hline $\mathrm{LAD}, n(\%)$ & $348(52.0))$ & $199(55.5)$ & 0.110 \\
\hline $\mathrm{RCA}, n(\%)$ & $243(36.3)$ & $117(32.7)$ & 0.114 \\
\hline LCX, $n(\%)$ & $57(8.5)$ & $37(10.3)$ & 0.252 \\
\hline Multi-vessel disease, $n(\%)$ & $269(38.4)$ & $125(34.9)$ & 0.278 \\
\hline Pre TIMI grade $0.1, n(\%)$ & $440(65.7)$ & $239(66.9)$ & 0.401 \\
\hline Post TIMI grade $3, n(\%)$ & $625(93.4)$ & $323(90.5)$ & 0.090 \\
\hline Peak CK level, mg/dL & $2062(932-3899)$ & $2096(973-3934)$ & 0.350 \\
\hline
\end{tabular}


Table 1. Cont.

\begin{tabular}{cccc}
\hline Variables & $\begin{array}{c}\text { Derivation Cohort } \\
(\boldsymbol{n}=\mathbf{6 6 9 )})\end{array}$ & $\begin{array}{c}\text { Validation Cohort } \\
(\boldsymbol{n}=\mathbf{3 5 8})\end{array}$ & $\boldsymbol{p}$-Value \\
\hline Mechanical support on admission & & & \\
Respirator, $n(\%)$ & $36(5.4)$ & $18(5.0)$ & 0.436 \\
Temporary pacing, $n(\%)$ & $51(7.6)$ & $33(9.2)$ & 0.238 \\
IABP, $n(\%)$ & $99(14.7)$ & $44(12.3)$ & 0.169 \\
PCPS, $n(\%)$ & $21(3.1)$ & $11(3.0)$ & 0.523 \\
In-hospital death, $n(\%)$ & $34(5.1)$ & $23(6.4)$ & 0.318 \\
\hline
\end{tabular}

Data for categorical variables are given as numbers (\%); data for continuous variables given as means \pm standard deviation for normal distribution or medians (interquartile range) for skewed distribution. BNP, brain natriuretic peptide; $\mathrm{BP}$, blood presser; $\mathrm{BS}$, blood sugar; $\mathrm{CABG}$, coronary artery bypass grafting; $\mathrm{CK}$, creatine kinase; CRP, C-reactive protein; eGFR, estimated glomerular filtration rate; HDL-CHO, high density lipoprotein cholesterol; $\mathrm{HR}$, heart rate; IABP, intra-aortic balloon pumping; LAD, left anterior descending; LCX, left circumflex; LDL-CHO, low density lipoprotein cholesterol; LMT, left main tank; LVEF, left ventricular ejection fraction; MI, myocardial infarction; PCI, percutaneous coronary intervention; PCPS, percutaneous cardiopulmonary support; RCA, right coronary artery; TIMI, thrombolysis in myocardial infarction; WBC, white blood cell.

\subsection{Blood Testing and Risk Stratification Model}

Table 2 shows the univariate analysis of the results of blood testing in the derivation cohort stratified by in-hospital survival or death. The variables that were significant by univariate analysis were subjected to multivariate stepwise forward logistic regression analysis, and 5 variables were found to be significantly associated with in-hospital death, as follows: platelet count $<15 \times 10^{4}$ (OR $3.45,95 \%$ confidence interval $(\mathrm{CI}) 1.50-7.97 ; p=0.003)$, BS $\geq 200 \mathrm{mg} / \mathrm{dL}$ (OR 2.63, 95\% CI 1.20-5.80; $p=$ 0.020 ), eGFR $<45 \mathrm{~mL} / \mathrm{min} / 1.73 \mathrm{~m}^{2}$ (OR $3.65,95 \%$ CI $1.80-8.11 ; p=0.001$ ), albumin $\leq 3.5 \mathrm{~g} / \mathrm{dL}$ (OR 3.37, $95 \%$ CI 1.52-7.47; $p=0.003$ ), and hsTnI $>1.6 \mathrm{ng} / \mathrm{mL}$ (OR 2.76; 95\% CI 1.27-6.01; $p=0.010)$. Based on their OR values, risk scores were assigned to the 5 variables (Table 3 ).

Table 2. Univariate analysis for in-hospital death in derivation cohort.

\begin{tabular}{|c|c|c|c|}
\hline Variables & Survivor & Death & $p$-Value \\
\hline $\mathrm{WBC}, \times 10^{2} / \mu \mathrm{L}$ & $105.9 \pm 1.5$ & $122.6 \pm 6.5$ & 0.013 \\
\hline Hemoglobin, g/dL & $14.0 \pm 2.1$ & $12.6 \pm 2.1$ & $<0.001$ \\
\hline Platelet, $\times 10^{4} / \mu \mathrm{L}$ & $22.1 \pm 0.6$ & $17.3 \pm 1.1$ & $<0.001$ \\
\hline $\mathrm{HbA} 1 \mathrm{c}, \%$ & $5.9(5.7-6.5)$ & $6.1(5.6-6.9)$ & 0.541 \\
\hline $\mathrm{BS}, \mathrm{mg} / \mathrm{dL}$ & 155 (129-194) & $200(159-291)$ & $<0.001$ \\
\hline $\mathrm{eGFR}, \mathrm{mL} / \mathrm{min} / 1.73 \mathrm{~m}^{2}$ & $68.5 \pm 0.9$ & $46.1 \pm 4.0$ & $<0.001$ \\
\hline LDL-CHO, mg/dL & $125.5 \pm 1.4$ & $117.3 \pm 6.1$ & 0.191 \\
\hline $\mathrm{HDL}-\mathrm{CHO}, \mathrm{mg} / \mathrm{dL}$ & $44.6 \pm 0.5$ & $43.5 \pm 2.0$ & 0.182 \\
\hline Albumin, mg/dL & $4.1 \pm 0.1$ & $3.4 \pm 0.1$ & $<0.001$ \\
\hline Uric acid, mg/dL & $5.9 \pm 0.1$ & $7.4 \pm 0.3$ & $<0.001$ \\
\hline $\mathrm{CRP}, \mathrm{mg} / \mathrm{dL}$ & $0.13(0.06-0.39)$ & $0.35(0.08-1.06)$ & 0.012 \\
\hline $\mathrm{CK}, \mathrm{U} / \mathrm{L}$ & $152(96-393)$ & $312(133-2148)$ & 0.005 \\
\hline $\begin{array}{l}\text { High-sensitivity troponin } \mathrm{I}, \mathrm{ng} / \mathrm{mL} \\
\text { (99th percentile for whole healthy adult population: } 0.026 \text { ) }\end{array}$ & $0.26(0.04-2.18)$ & $2.32(0.29-40.4)$ & $<0.001$ \\
\hline $\mathrm{BNP}, \mathrm{pg} / \mathrm{mL}$ & $44.9(16.8-138.0)$ & $240(55.4-805)$ & $<0.001$ \\
\hline
\end{tabular}

Data for continuous variables are given as means \pm standard deviation for normal distribution or medians (interquartile range) for skewed distribution. BNP, brain natriuretic peptide; BS, blood sugar; $\mathrm{CK}$, creatine kinase; CRP, C-reactive protein; eGFR, estimated glomerular filtration rate; HDL-CHO, high density lipoprotein cholesterol; LDL-CHO, low density lipoprotein cholesterol; WBC, white blood cell.

Table 3. Multivariate logistic regression in derivation cohort and corresponding risk score for in-hospital death.

\begin{tabular}{ccccc}
\hline Variables & Odds Ratio & $\mathbf{9 5 \%}$ Confidence Interval & $p$-Value & Given Score \\
\hline Platelet $<15 \times 10^{4} / \mu \mathrm{L}$ & 3.45 & $1.50-7.97$ & 0.003 & 2 points \\
BS $\geq 200 \mathrm{mg} / \mathrm{dL}$ & 2.63 & $1.20-5.80$ & 0.020 & 1 point \\
$\mathrm{eGFR}<45 \mathrm{~mL} / \mathrm{min} / 1.73 \mathrm{~m}^{2}$ & 3.65 & $1.60-8.11$ & 0.001 & 2 points \\
Albumin $\leq 3.5 \mathrm{mg} / \mathrm{dL}$ & 3.37 & $1.52-7.47$ & 0.003 & 2 points \\
High-sensitivity troponin I $>1.6 \mathrm{ng} / \mathrm{dL}$ & 2.76 & $1.27-6.01$ & 0.010 & 1 point \\
(normal upper limit $\times 50$ ) & & & & \\
\hline
\end{tabular}

BS, blood sugar; eGFR, estimated glomerular filtration rate. 


\subsection{Prediction of In-Hospital Mortality}

No significant differences were found between the in-hospital mortality of the 2 patient cohorts (5.1\% for derivation cohort vs. $6.4 \%$ in the validation cohort, $p=0.318)$. In the derivation cohort, an increased total risk score was significantly associated with elevated in-hospital mortality $(p<0.001)$ (Figure 2A). Therefore, we assessed the utility of this risk score in the validation cohort. The risk score also showed a significant trend for in-hospital mortality in the validation cohort $(p<0.001)$ (Figure 2B). Additionally, we classified the patients into 3 groups according to risk score to simplify its use in clinical settings. Low-risk group ( 0 to 1 point), moderate-risk group ( 2 to 4 points), high-risk group ( $\geq 5$ points). These risk groups also showed a significant trend for in-hospital mortality among the respective validation and derivation cohorts (low-risk $1.4 \%$ and $0.8 \%$, moderate-risk $8.8 \%$ and $12.2 \%$, and high-risk $29.8 \%$ and $35.8 \% ; p<0.001$ ) (Figure 3). The risk score displayed adequate discrimination between patients with or without in-hospital death in both the validation (AUC: 0.853 , 95\% CI 0.782-0.904) and derivation cohorts (AUC: 0.879, 95\% CI 0.791-0.933) (Figure 4).
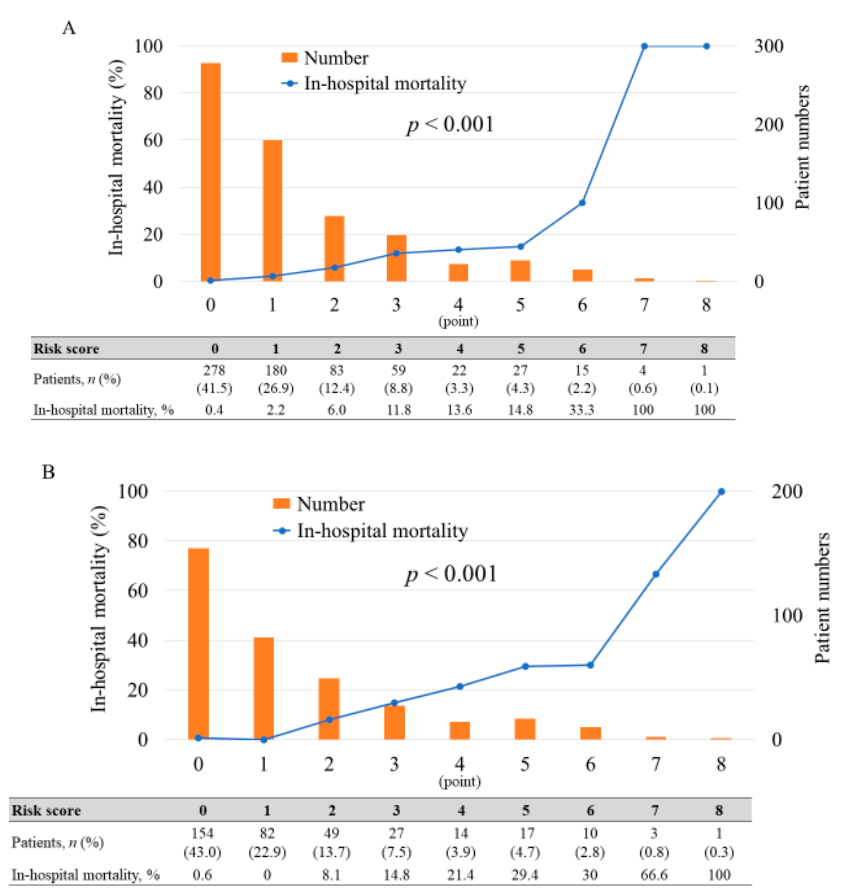

Figure 2. Distribution of risk scores and risk of in-hospital mortality (A) derivation cohort and (B) validation cohort.
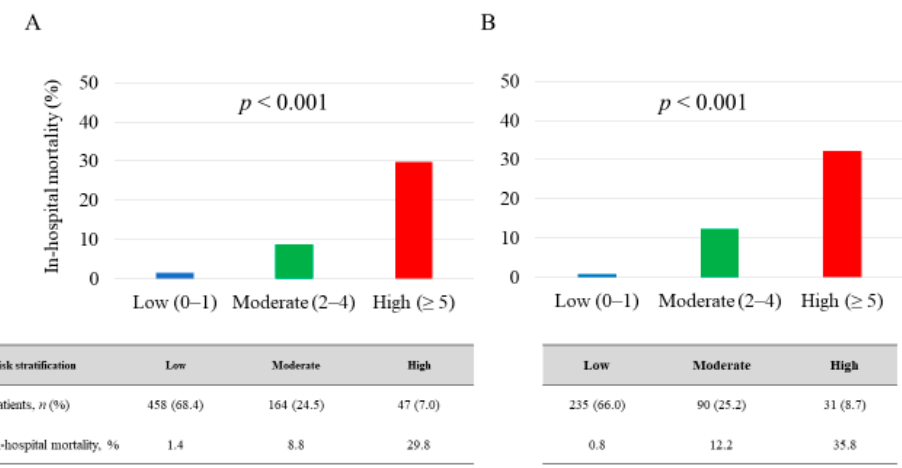

Figure 3. Risk stratification for predicting in-hospital mortality. (A) derivation cohort and (B) validation cohort. The low-, moderate-, and high-risk groups have scores assigned as follows: $0-1,2-4$, and $\geq 5$, respectively. 
A

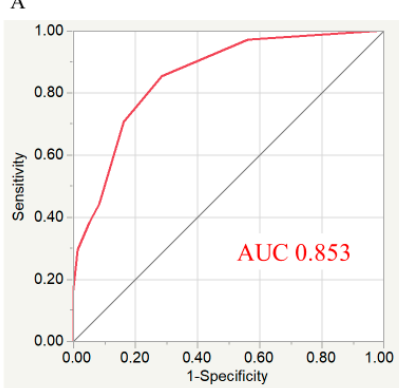

B

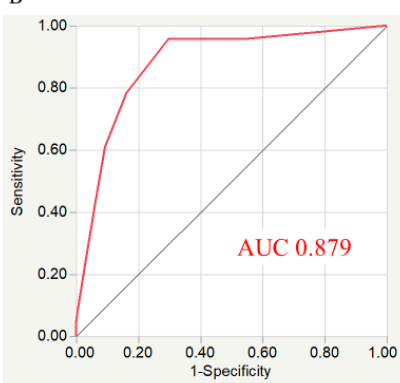

Figure 4. Receiver operating characteristic (ROC) curves of laboratory risk score. (A) Area under the curve (AUC) was 0.853 (95\% confidence interval (CI) 0.782-0.904) for derivation cohort. (B) AUC was 0.879 (95\% CI 0.791-0.933) for validation cohort.

\subsection{Comparison of New Risk Score with GRACE Risk Score}

The AUCs of the laboratory risk score and GRACE risk score in the validation cohort were 0.879 (95\% CI 0.791-0.933) and 0.891 (95\% CI 0.773-0.952), respectively (Figure 5A). The difference between the AUCs was not significant $(p=0.721)$. Furthermore, when patients in the 3 laboratory risk-score groups $(0-1,2-4$, and $\geq 5)$ were subdivided into the low-intermediate (GRACE risk score $<155)$ or high-risk $(\geq 155)$ subgroups, [23] our laboratory-based risk model could further stratify the risk of in-hospital mortality even in the high-risk patients identified by the GRACE risk score, as well as in the low-intermediate risk patients (Figure 5B).
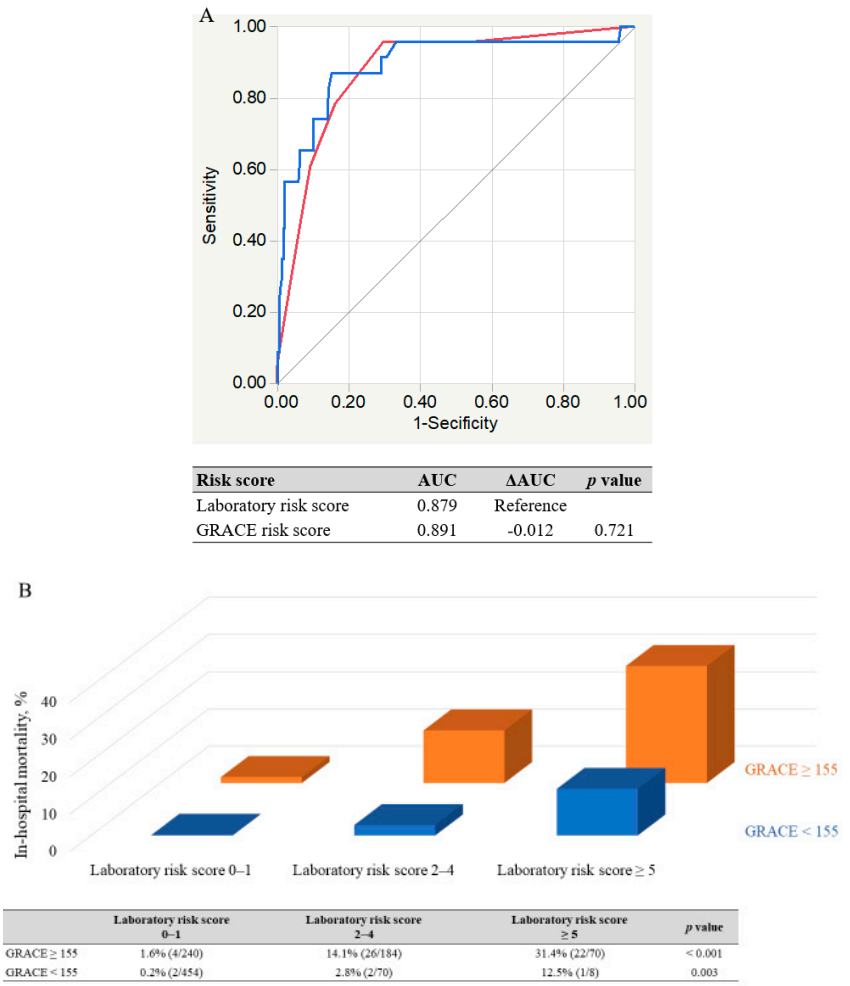

Figure 5. Comparison between laboratory risk score and Global Registry of Acute Coronary Events (GRACE) risk score. (A) Area under the curves (AUCs) of laboratory risk score (red) and GRACE risk score (blue) in validation cohort were 0.879 (95\% confidence interval (CI) 0.790-0.931) and 0.891 (95\% CI 0.773-0.952), respectively, and the difference was not significant. (B) Substratification by the combined laboratory parameter risk scores of all patients stratified according to GRACE risk scores. Table below graph shows in-hospital mortality for each stratified population. AUC, area under the curve; CI, confidence interval; GRACE, Global Registry of Acute Coronary Events. 


\section{Discussion}

The major findings of this study of patients with STEMI undergoing primary PCI were as follows: (1) each of 5 laboratory parameters quantified at admission (eGFR $<45 \mathrm{~mL} / \mathrm{min} / 1.73 \mathrm{~m}^{2}$, platelet count $<15 \times 10^{4} / \mu \mathrm{L}$, albumin level $\leq 3.5 \mathrm{~g} / \mathrm{dL}$, hsTnI level $>1.6 \mathrm{ng} / \mathrm{mL}$, and BS level $\geq 200 \mathrm{mg} / \mathrm{dL}$ ) was independently associated with increased in-hospital mortality; (2) the risk-weighted combined-score model based on these laboratory parameters could incrementally provide an accurate prediction of in-hospital mortality; (3) the predictive value of this model for in-hospital mortality was comparable to that of the conventional GRACE risk score model, and our model could further stratify that risk, especially for high-risk patients as identified by the GRACE model. Thus, our results suggest that this laboratory-based risk model can enable the objective and accurate prediction of the risk of in-hospital mortality in STEMI patients who underwent primary PCI within $48 \mathrm{~h}$ after onset.

All patients with STEMI seen in the emergency department are required to receive a prompt risk assessment of cardiovascular complications and the short-term prognosis [1]. In this study, we focused on the results of routine blood tests to develop an objective risk score model for predicting in-hospital mortality in patients with STEMI. Several established risk models, including the TIMI and GRACE risk scores, use vital signs and the Killip classification in their evaluations [9,10]. However, those variables often vary widely, especially in the acute clinical setting; and Killip classification is a subjective evaluation based on the physical examination. The patient's retrospective clinical history is also needed for these models, and it can be difficult to obtain from patients with such clinical conditions as shock and cardiac arrest. By contrast, the results of blood tests can be quickly and easily obtained, even in the emergency setting, and will provide completely objective information. Biomarkers can be also time-varying during acute presentation of STEMI. However, there was no significant difference in the onset-to-admission time between in-hospital survival group and death group in our study, suggesting the higher levels of biomarkers in the death group were at least unlikely due to later presentation and/or sampling. Given the study findings that our laboratory-based risk score model could provide adequate discrimination between patients with and without in-hospital death that is comparable to that provided by the GRACE risk score, our model should help us provide a more objective assessment than that provided by the GRACE model for the short-term risk of mortality in STEMI patients after successful primary PCI.

Several biomarkers that are related to cardiac, metabolic, hematologic, and inflammatory responses have been reported to be independent predictors of in-hospital mortality in patients with STEMI [13-20]. Our laboratory-based risk model was composed of 5 variables (platelet count and levels of BS, albumin, eGFR, and hsTnI) obtained from routine admission blood tests. Each of these variables has also been demonstrated to be independently associated with increased risk of poor prognosis in patients with acute coronary syndrome (ACS), including STEMI [24-28]. These biomarkers are likely associated with not only acute pathophysiological responses such as inflammation and cardiac direct injury that resulted from the development of an AMI, but also with the patient's general conditions, including metabolic conditions and nutrition. Interestingly, an elevated level of BS, but not HbA1c, was associated with mortality in both univariate and multivariate analyses. This finding suggests that hyperglycemia possibly as a reflection of an acute stress response, rather than underlying and longer-term diabetes status which is a well-known risk factor for development of AMI, is associated with short-term mortality. Thus, these particular laboratory parameters reflect a broad range of pathophysiological information within individuals, and the combined use of these biomarkers therefore has the potential for estimating the risk of mortality in a comprehensive and objective manner.

To date, several studies have reported on the combined use of laboratory-only parameters in risk models for in-hospital mortality in patients with ACS, including STEMI [29-33]. Compared with models that use novel biomarkers, such as copeptin and suppression of tumorigenicity 2 [31,32], our model should be easy to perform in the actual clinical setting. Yanishi et al. [33] also reported a simple risk stratification model that was based on the combined use of laboratory parameters to predict in-hospital mortality in Japanese patients with STEMI. In that study, the authors found that 
a risk-weighted combination model containing the 5 following variables: WBC count and levels of hemoglobin, CRP, creatinine, and BS, could predict that risk. The performance of their model was comparable to that of the TIMI risk score model [34]. Although the actual reasons for the some of the different variables identified by Yanishi et al. versus those identified for our model are unclear, differences between the study cohorts might in part play a role. For example, the study by Yanishi et al. included all patients with STEMI, regardless of whether they were receiving primary PCI and regardless of onset-to-door time. We excluded those patients who did not undergo primary PCI or were admitted $>48 \mathrm{~h}$ after onset. The rates of in-hospital death were also relatively different between the 2 models (Yanishi's model 10.8\% and our model 5.6\%), suggesting that the difference between the extents of severity in study populations affected the selection of variables.

BNP was associated with in-hospital death in the univariate analysis, but not in the multivariate logistic regression. Because potential risk markers were eliminated by multivariate logistic regression using stepwise factor elimination method in the present study, it might be difficult to determine a precise reason for elimination of BNP, as well as other parameters eliminated in the multivariate regression analysis. Measurement of BNP is widely known to improve risk stratification for mortality in patients with STEMI beyond baseline clinical variables [17,35]. On the basis of previous evidence [36], the time-course of the plasma BNP levels in patients with AMI could be divided into two patterns: a monophasic pattern with one peak at about $16 \mathrm{~h}$ after admission and a biphasic pattern with two peaks at about $16 \mathrm{~h}$ after admission, reflecting acute response to ischemia, and 5 days after admission, reflecting increased wall stress due to cardiac remodeling. The biphasic pattern was associated with severe left ventricular damages and dysfunction. In addition, Suzuki et al. [37] reported that the plasma BNP levels obtained 3 to 4 weeks after the onset of AMI was an independent predictor of cardiac death in patients with AMI. In our study, the BNP levels were measured immediately after admission, and the onset-to-admission time was median $200 \mathrm{~min}$. Thus, the BNP levels obtained in our study unlikely reached at the clinically meaningful levels, and it might be too short and low to predict in-hospital mortality.

Our laboratory-based risk model was found to provide an accuracy for predicting in-hospital mortality that was similar to that provided by the conventional GRACE risk model. Additionally, our model could further stratify that risk, especially for high-risk patients as identified by the GRACE score. The GRACE score is known to provide several types of information for risk stratification upon admission, including prediction of risk of not only in-hospital mortality, but also 6-month mortality after discharge $[38,39]$. Moreover, in a Japanese registry of STEMI patients, during a median follow up of 3.9 years for patients with GRACE scores $<100,101-120,121-140$, and $\geq 141$, the mortality rates were $2.0 \%, 6.3 \%, 11.8 \%$, and $16.8 \%$, respectively [40]. These results suggest that the GRACE score is useful for predicting the outcomes of patients after STEMI, even during the chronic phase. However, whether or not our laboratory-based model can also predict long-term outcomes is currently unknown. Therefore, further research is warranted to assess the predictive power of our model for long-term outcome.

This study has limitations. First, this was a single-center, retrospective, observational study of a relatively small sample. Second, our inclusion of only those patients with STEMI who underwent primary PCI and were admitted within $48 \mathrm{~h}$ after onset could result in bias. Furthermore, the rate of in-hospital mortality was relatively low. Thus, our findings might not be applicable to STEMI patients with other clinical scenarios and different extents of severity. Importantly, we only enrolled Japanese patients, and therefore our findings might only be applicable to this population. Third, this study evaluated laboratory parameters only upon admission for STEMI. Thus, determining if the values of the parameters reflect acute pathophysiological changes associated with STEMI or associated with background status is difficult. In addition, the laboratory parameters obtained after primary PCI, such as lactate and maximum level of $\mathrm{CK}$, were not considered for the current model due to the concept of the study. Finally, we did not take into account any other non-laboratory clinical factors for the risk stratification of in-hospital mortality, including age and sex, cardiac function, duration of ischemia, and perioperative complications. Especially, it has been reported that there were some sex-differences 
in outcomes after AMI and their predictive markers [41-43], however, we could not tease out any sex-dependent issues due to a limited proportion of female population in our cohorts. Although our risk score model showed a performance comparable to that of the GRACE score, further research is thus needed to assess whether the other clinical factors could increase the predictive value for outcome in patients with STEMI.

\section{Conclusions}

The novel laboratory-based model developed for our study cohorts may be helpful for providing an objective and accurate prediction of the risk of in-hospital mortality in STEMI patients who undergo primary PCI within $48 \mathrm{~h}$ after onset. The overall accuracy of our model for predicting in-hospital mortality was comparable to that of the conventional GRACE risk model, and our model could stratify that risk further, especially for high-risk patients.

Author Contributions: Conceptualization, Y.G. and A.T.; methodology, Y.G.; validation, A.K.; formal analysis, Y.G. and A.K.; investigation, K.N. (Kensaku Nishihira), M.N., N.W., K.A., and N.K. data curation, K.N. (Kensaku Nishihira), M.N., N.W., K.A., and N.K.; writing—original draft preparation, Y.G. and A.T.; writing-review and editing, K.N. (Kensaku Nishihira), A.K., M.N., N.W., K.A., N.K., Y.S., and K.N. (Koichi Node); visualization, Y.G. and A.T.; supervision, Y.S. and K.N. (Koichi Node); project administration, Y.G., A.T., K.N. (Kensaku Nishihira), A.K., M.N., N.W., K.A., N.K., Y.S., and K.N. (Koichi Node). All authors have read and agreed to the published version of the manuscript.

Funding: This research received no external funding.

Acknowledgments: The authors thank Aya Yamada (Saga University) for her excellent support.

Conflicts of Interest: All authors declare no competing interests.

\section{References}

1. Ibanez, B.; James, S.; Agewall, S.; Antunes, M.J.; Bucciarelli-Ducci, C.; Bueno, H.; Caforio, A.L.P.; Crea, F.; Goudevenos, J.A.; Halvorsen, S.; et al. 2017 ESC Guidelines for the management of acute myocardial infarction in patients presenting with ST-segment elevation: The Task Force for the management of acute myocardial infarction in patients presenting with ST-segment elevation of the European Society of Cardiology (ESC). Eur. Heart J. 2018, 39, 119-177. [CrossRef] [PubMed]

2. Puymirat, E.; Simon, T.; Cayla, G.; Cottin, Y.; Elbaz, M.; Coste, P.; Lemesle, G.; Motreff, P.; Popovic, B.; Khalife, K.; et al. Acute Myocardial Infarction: Changes in Patient Characteristics, Management, and 6-Month Outcomes Over a Period of 20 Years in the FAST-MI Program (French Registry of Acute ST-Elevation or Non-ST-Elevation Myocardial Infarction) 1995 to 2015. Circulation 2017, 136, 1908-1919. [CrossRef] [PubMed]

3. Degano, I.R.; Salomaa, V.; Veronesi, G.; Ferrieres, J.; Kirchberger, I.; Laks, T.; Havulinna, A.S.; Ruidavets, J.B.; Ferrario, M.M.; Meisinger, C.; et al. Twenty-five-year trends in myocardial infarction attack and mortality rates, and case-fatality, in six European populations. Heart 2015, 101, 1413-1421. [CrossRef] [PubMed]

4. Schmidt, M.; Jacobsen, J.B.; Lash, T.L.; Botker, H.E.; Sorensen, H.T. 25 year trends in first time hospitalisation for acute myocardial infarction, subsequent short and long term mortality, and the prognostic impact of sex and comorbidity: A Danish nationwide cohort study. BMJ 2012, 344, e356. [CrossRef] [PubMed]

5. Cui, Y.; Hao, K.; Takahashi, J.; Miyata, S.; Shindo, T.; Nishimiya, K.; Kikuchi, Y.; Tsuburaya, R.; Matsumoto, Y.; Ito, K.; et al. Age-Specific Trends in the Incidence and In-Hospital Mortality of Acute Myocardial Infarction Over 30 Years in Japan- Report from the Miyagi AMI Registry Study. Circ. J. Off. J. Jpn. Circ. Soc. 2017, 81, 520-528. [CrossRef]

6. Miyachi, H.; Takagi, A.; Miyauchi, K.; Yamasaki, M.; Tanaka, H.; Yoshikawa, M.; Saji, M.; Suzuki, M.; Yamamoto, T.; Shimizu, W.; et al. Current characteristics and management of ST elevation and non-ST elevation myocardial infarction in the Tokyo metropolitan area: From the Tokyo CCU network registered cohort. Heart Vessel. 2016, 31, 1740-1751. [CrossRef]

7. Menees, D.S.; Peterson, E.D.; Wang, Y.; Curtis, J.P.; Messenger, J.C.; Rumsfeld, J.S.; Gurm, H.S. Door-to-balloon time and mortality among patients undergoing primary PCI. N. Engl. J. Med. 2013, 369, 901-909. [CrossRef] 
8. Shiomi, H.; Nakagawa, Y.; Morimoto, T.; Furukawa, Y.; Nakano, A.; Shirai, S.; Taniguchi, R.; Yamaji, K.; Nagao, K.; Suyama, T.; et al. Association of onset to balloon and door to balloon time with long term clinical outcome in patients with ST elevation acute myocardial infarction having primary percutaneous coronary intervention: Observational study. BMJ 2012, 344, e3257. [CrossRef]

9. Granger, C.B.; Goldberg, R.J.; Dabbous, O.; Pieper, K.S.; Eagle, K.A.; Cannon, C.P.; Van De Werf, F.; Avezum, A.; Goodman, S.G.; Flather, M.D.; et al. Predictors of hospital mortality in the global registry of acute coronary events. Arch. Intern. Med. 2003, 163, 2345-2353. [CrossRef]

10. Morrow, D.A.; Antman, E.M.; Parsons, L.; de Lemos, J.A.; Cannon, C.P.; Giugliano, R.P.; McCabe, C.H.; Barron, H.V.; Braunwald, E. Application of the TIMI risk score for ST-elevation MI in the National Registry of Myocardial Infarction 3. JAMA 2001, 286, 1356-1359. [CrossRef]

11. Komiyama, K.; Nakamura, M.; Tanabe, K.; Niikura, H.; Fujimoto, H.; Oikawa, K.; Daida, H.; Yamamoto, T.; Nagao, K.; Takayama, M. In-hospital mortality analysis of Japanese patients with acute coronary syndrome using the Tokyo CCU Network database: Applicability of the GRACE risk score. J. Cardiol. 2018, 71, 251-258. [CrossRef] [PubMed]

12. Abu-Assi, E.; Ferreira-Gonzalez, I.; Ribera, A.; Marsal, J.R.; Cascant, P.; Heras, M.; Bueno, H.; Sanchez, P.L.; Aros, F.; Marrugat, J.; et al. Do GRACE (Global Registry of Acute Coronary events) risk scores still maintain their performance for predicting mortality in the era of contemporary management of acute coronary syndromes? Am. Heart J. 2010, 160, e821-e823. [CrossRef] [PubMed]

13. Wester, A.; Attar, R.; Mohammad, M.A.; Andell, P.; Hofmann, R.; Jensen, J.; Szummer, K.; Erlinge, D.; Koul, S. Impact of Baseline Anemia in Patients with Acute Coronary Syndromes Undergoing Percutaneous Coronary Intervention: A Prespecified Analysis from the VALIDATE-SWEDEHEART Trial. J. Am. Heart Assoc. 2019, 8, e012741. [CrossRef] [PubMed]

14. Wei, P.; Fu, Q.; Tao, Z.Q.; Han, B.; Zhang, Y.G.; Huang, Y.J.; Ling, L.; Yang, X.J. Relationship between B-type natriuretic peptide and short-term prognosis in non-diabetic patients with ST-segment elevation myocardial infarction. Eur. Rev. Med. Pharmacol. Sci. 2016, 20, 721-725. [PubMed]

15. Oduncu, V.; Erkol, A.; Karabay, C.Y.; Kurt, M.; Akgun, T.; Bulut, M.; Pala, S.; Kirma, C. The prognostic value of serum albumin levels on admission in patients with acute ST-segment elevation myocardial infarction undergoing a primary percutaneous coronary intervention. Coron. Artery Dis. 2013, 24, 88-94. [CrossRef] [PubMed]

16. Moriyama, N.; Ishihara, M.; Noguchi, T.; Nakanishi, M.; Arakawa, T.; Asaumi, Y.; Kumasaka, L.; Kanaya, T.; Miyagi, T.; Nagai, T.; et al. Admission hyperglycemia is an independent predictor of acute kidney injury in patients with acute myocardial infarction. Circ. J. Off. J. Jpn. Circ. Soc. 2014, 78, 1475-1480. [CrossRef] [PubMed]

17. Mega, J.L.; Morrow, D.A.; De Lemos, J.A.; Sabatine, M.S.; Murphy, S.A.; Rifai, N.; Gibson, C.M.; Antman, E.M.; Braunwald, E. B-type natriuretic peptide at presentation and prognosis in patients with ST-segment elevation myocardial infarction: An ENTIRE-TIMI-23 substudy. J. Am. Coll. Cardiol. 2004, 44, 335-339. [CrossRef]

18. Kaya, M.G.; Uyarel, H.; Akpek, M.; Kalay, N.; Ergelen, M.; Ayhan, E.; Isik, T.; Cicek, G.; Elcik, D.; Sahin, O.; et al. Prognostic value of uric acid in patients with ST-elevated myocardial infarction undergoing primary coronary intervention. Am. J. Cardiol. 2012, 109, 486-491. [CrossRef]

19. Gibson, C.M.; Pinto, D.S.; Murphy, S.A.; Morrow, D.A.; Hobbach, H.P.; Wiviott, S.D.; Giugliano, R.P.; Cannon, C.P.; Antman, E.M.; Braunwald, E. Association of creatinine and creatinine clearance on presentation in acute myocardial infarction with subsequent mortality. J. Am. Coll. Cardiol. 2003, 42, 1535-1543. [CrossRef]

20. Wanamaker, B.L.; Seth, M.M.; Sukul, D.; Dixon, S.R.; Bhatt, D.L.; Madder, R.D.; Rumsfeld, J.S.; Gurm, H.S. Relationship Between Troponin on Presentation and In-Hospital Mortality in Patients With ST-Segment-Elevation Myocardial Infarction Undergoing Primary Percutaneous Coronary Intervention. J. Am. Heart Assoc. 2019, 8, e013551. [CrossRef]

21. Thygesen, K.; Alpert, J.S.; Jaffe, A.S.; Chaitman, B.R.; Bax, J.J.; Morrow, D.A.; White, H.D. Fourth Universal Definition of Myocardial Infarction (2018). Circulation 2018, 138, e618-e651. [CrossRef] [PubMed]

22. Matsuo, S.; Imai, E.; Horio, M.; Yasuda, Y.; Tomita, K.; Nitta, K.; Yamagata, K.; Tomino, Y.; Yokoyama, H.; Hishida, A. Revised equations for estimated GFR from serum creatinine in Japan. American journal of kidney diseases. Off. J. Natl. Kidney Found. 2009, 53, 982-992. [CrossRef] [PubMed] 
23. Yan, A.T.; Yan, R.T.; Cantor, W.J.; Borgundvaag, B.; Cohen, E.A.; Fitchett, D.H.; Dzavik, V.; Ducas, J.; Tan, M.; Casanova, A.; et al. Relationship between risk stratification at admission and treatment effects of early invasive management following fibrinolysis: Insights from the Trial of Routine ANgioplasty and Stenting After Fibrinolysis to Enhance Reperfusion in Acute Myocardial Infarction (TRANSFER-AMI). Eur. Heart J. 2011, 32, 1994-2002. [CrossRef] [PubMed]

24. Hakim, D.A.; Dangas, G.D.; Caixeta, A.; Nikolsky, E.; Lansky, A.J.; Moses, J.W.; Claessen, B.; Sanidas, E.; White, H.D.; Ohman, E.M.; et al. Impact of baseline thrombocytopenia on the early and late outcomes after ST-elevation myocardial infarction treated with primary angioplasty: Analysis from the Harmonizing Outcomes with Revascularization and Stents in Acute Myocardial Infarction (HORIZONS-AMI) trial. Am. Heart J. 2011, 161, 391-396. [CrossRef] [PubMed]

25. Singh, K.; Hibbert, B.; Singh, B.; Carson, K.; Premaratne, M.; Le May, M.; Chong, A.Y.; Arstall, M.; So, D. Meta-analysis of admission hyperglycaemia in acute myocardial infarction patients treated with primary angioplasty: A cause or a marker of mortality? European heart journal. Cardiovasc. Pharmacother. 2015, 1, 220-228. [CrossRef]

26. Gonzalez-Pacheco, H.; Amezcua-Guerra, L.M.; Sandoval, J.; Martinez-Sanchez, C.; Ortiz-Leon, X.A.; Pena-Cabral, M.A.; Bojalil, R. Prognostic Implications of Serum Albumin Levels in Patients With Acute Coronary Syndromes. Am. J. Cardiol. 2017, 119, 951-958. [CrossRef]

27. Anavekar, N.S.; McMurray, J.J.; Velazquez, E.J.; Solomon, S.D.; Kober, L.; Rouleau, J.L.; White, H.D.; Nordlander, R.; Maggioni, A.; Dickstein, K.; et al. Relation between renal dysfunction and cardiovascular outcomes after myocardial infarction. N. Engl. J. Med. 2004, 351, 1285-1295. [CrossRef]

28. Antman, E.M.; Tanasijevic, M.J.; Thompson, B.; Schactman, M.; McCabe, C.H.; Cannon, C.P.; Fischer, G.A.; Fung, A.Y.; Thompson, C.; Wybenga, D.; et al. Cardiac-specific troponin I levels to predict the risk of mortality in patients with acute coronary syndromes. N. Engl. J. Med. 1996, 335, 1342-1349. [CrossRef]

29. Sabatine, M.S.; Morrow, D.A.; de Lemos, J.A.; Gibson, C.M.; Murphy, S.A.; Rifai, N.; McCabe, C.; Antman, E.M.; Cannon, C.P.; Braunwald, E. Multimarker approach to risk stratification in non-ST elevation acute coronary syndromes: Simultaneous assessment of troponin I, C-reactive protein, and B-type natriuretic peptide. Circulation 2002, 105, 1760-1763. [CrossRef]

30. Damman, P.; Beijk, M.A.; Kuijt, W.J.; Verouden, N.J.; van Geloven, N.; Henriques, J.P.; Baan, J.; Vis, M.M.; Meuwissen, M.; van Straalen, J.P.; et al. Multiple biomarkers at admission significantly improve the prediction of mortality in patients undergoing primary percutaneous coronary intervention for acute ST-segment elevation myocardial infarction. J. Am. Coll. Cardiol. 2011, 57, 29-36. [CrossRef]

31. O'Malley, R.G.; Bonaca, M.P.; Scirica, B.M.; Murphy, S.A.; Jarolim, P.; Sabatine, M.S.; Braunwald, E.; Morrow, D.A. Prognostic performance of multiple biomarkers in patients with non-ST-segment elevation acute coronary syndrome: Analysis from the MERLIN-TIMI 36 trial (Metabolic Efficiency with Ranolazine for Less Ischemia in Non-ST-Elevation Acute Coronary Syndromes-Thrombolysis in Myocardial Infarction 36). J. Am. Coll. Cardiol. 2014, 63, 1644-1653. [CrossRef] [PubMed]

32. O’Donoghue, M.L.; Morrow, D.A.; Cannon, C.P.; Jarolim, P.; Desai, N.R.; Sherwood, M.W.; Murphy, S.A.; Gerszten, R.E.; Sabatine, M.S. Multimarker Risk Stratification in Patients With Acute Myocardial Infarction. J. Am. Heart Assoc. 2016, 5. [CrossRef] [PubMed]

33. Yanishi, K.; Nakamura, T.; Nakanishi, N.; Yokota, I.; Zen, K.; Yamano, T.; Shiraishi, H.; Shirayama, T.; Shiraishi, J.; Sawada, T.; et al. A Simple Risk Stratification Model for ST-Elevation Myocardial Infarction (STEMI) from the Combination of Blood Examination Variables: Acute Myocardial Infarction-Kyoto Multi-Center Risk Study Group. PLoS ONE 2016, 11, e0166391. [CrossRef] [PubMed]

34. Morrow, D.A.; Antman, E.M.; Giugliano, R.P.; Cairns, R.; Charlesworth, A.; Murphy, S.A.; de Lemos, J.A.; McCabe, C.H.; Braunwald, E. A simple risk index for rapid initial triage of patients with ST-elevation myocardial infarction: An InTIME II substudy. Lancet 2001, 358, 1571-1575. [CrossRef]

35. Scirica, B.M.; Kadakia, M.B.; de Lemos, J.A.; Roe, M.T.; Morrow, D.A.; Li, S.; Wiviott, S.D.; Kontos, M.C. Association between natriuretic peptides and mortality among patients admitted with myocardial infarction: A report from the ACTION Registry(R)-GWTG ${ }^{\mathrm{TM}}$. Clin. Chem. 2013, 59, 1205-1214. [CrossRef] [PubMed]

36. Morita, E.; Yasue, H.; Yoshimura, M.; Ogawa, H.; Jougasaki, M.; Matsumura, T.; Mukoyama, M.; Nakao, K. Increased plasma levels of brain natriuretic peptide in patients with acute myocardial infarction. Circulation 1993, 88, 82-91. [CrossRef] 
37. Suzuki, S.; Yoshimura, M.; Nakayama, M.; Mizuno, Y.; Harada, E.; Ito, T.; Nakamura, S.; Abe, K.; Yamamuro, M.; Sakamoto, T.; et al. Plasma level of B-type natriuretic peptide as a prognostic marker after acute myocardial infarction: A long-term follow-up analysis. Circulation 2004, 110, 1387-1391. [CrossRef]

38. Fox, K.A.; Dabbous, O.H.; Goldberg, R.J.; Pieper, K.S.; Eagle, K.A.; Van de Werf, F.; Avezum, A.; Goodman, S.G.; Flather, M.D.; Anderson, F.A., Jr.; et al. Prediction of risk of death and myocardial infarction in the six months after presentation with acute coronary syndrome: Prospective multinational observational study (GRACE). BMJ 2006, 333, 1091. [CrossRef]

39. Eagle, K.A.; Lim, M.J.; Dabbous, O.H.; Pieper, K.S.; Goldberg, R.J.; Van de Werf, F.; Goodman, S.G.; Granger, C.B.; Steg, P.G.; Gore, J.M.; et al. A validated prediction model for all forms of acute coronary syndrome: Estimating the risk of 6-month postdischarge death in an international registry. JAMA 2004, 291, 2727-2733. [CrossRef]

40. Nakatani, D.; Sakata, Y.; Suna, S.; Usami, M.; Matsumoto, S.; Shimizu, M.; Hara, M.; Uematsu, M.; Fukunami, M.; Hamasaki, T.; et al. Impact of beta blockade therapy on long-term mortality after ST-segment elevation acute myocardial infarction in the percutaneous coronary intervention era. Am. J. Cardiol. 2013, 111, 457-464. [CrossRef]

41. Canto, J.G.; Rogers, W.J.; Goldberg, R.J.; Peterson, E.D.; Wenger, N.K.; Vaccarino, V.; Kiefe, C.I.; Frederick, P.D.; Sopko, G.; Zheng, Z.J. Association of age and sex with myocardial infarction symptom presentation and in-hospital mortality. JAMA 2012, 307, 813-822. [CrossRef] [PubMed]

42. Rao, U.; Buchanan, G.L.; Hoye, A. Outcomes after percutaneous coronary intervention in women: Are there differences when compared with men? Interv. Cardiol. 2019, 14, 70-75. [CrossRef] [PubMed]

43. Wang, P.; Yao, J.; Xie, Y.; Luo, M. Gender-specific predictive markers of poor prognosis for patients with acute myocardial infarction during a 6-month follow-up. J. Cardiovasc. Transl. Res. 2020, 13, 27-38. [CrossRef] [PubMed]

(C) 2020 by the authors. Licensee MDPI, Basel, Switzerland. This article is an open access article distributed under the terms and conditions of the Creative Commons Attribution (CC BY) license (http://creativecommons.org/licenses/by/4.0/). 